УДК $122 ; 14,140.8,141.1$

DOI: 10.18101/1994-0866-2020-3-68-76

\title{
ОСМЫСЛЕНИЕ ОСНОВАНИЙ БЫТИЯ КУЛЬТУРЫ В КОНТЕКСТЕ ФИЛОСОФСКИХ МЕТАФОР ОГНЯ
}

\author{
(c) Моисеенко Татьяна Николаевна \\ аспирант кафедры философских наук, \\ Челябинский государственный институт культуры \\ Россия, 454091, г. Челябинск, ул. Орджоникидзе, 36А, корп. 1 \\ tanechka_70@mail.ru
}

\begin{abstract}
Аннотация. В статье обосновывается потенциал метафор, связанных с феноменом огня, для осмысления и интерпретации культуры в философских концепциях Ф. Ницше, О. Шпенглера, 3. Фрейда и П. Сорокина. Автором обосновывается эвристическое значение метафор огня в философско-культурологическом дискурсе. Представлены роль метафор в качестве самостоятельных средств философского мышления о «недосягаемом», средств визуализации философских идей и значение метафор огня в понимании оснований (начал) культуры, акцентируется внимание на проблеме динамики культуры, также представлена демонстрация возможностей метафор (как обоснование авторского тезиса о возможностях и значении метафоры огня) в анализе содержания и существа концепций культуры, указанных выше авторов. Проблема начала культуры связана с выявлением энергетического (творческого) принципа ее бытия, что отражено в авторском заключении-выводе.
\end{abstract}

Ключевые слова: философия; культура; метафора; огонь; начало; энергия; метафора огня; бытие культуры.

\section{Для цитирования}

Моисеенко Т. Н. Осмысление оснований бытия культуры в контексте философских метафор огня // Вестник Бурятского государственного университета. Философия. 2020. Вып. 3. С. 68-76.

Одним из сущностных характеристик философии всегда остаются постановка и решение проблем бытия человека, культуры, общества, истории с позиции так называемых «вечных» вопросов в их актуальной интерпретации. Своеобразие философской интерпретации в том, что философские идеи, темы живут особым способом, заново проблематизируясь с появлением новых контекстов, в изменившихся социокультурных условиях, в новом времени, при этом оставаясь открытыми для последующих интерпретаций. Кроме того, философское творчество всегда имеет глубоко личностный характер, поэтому тематизация любого предмета предполагает, как отмечал В. И. Плотников, «оформившуюся в мыслях автора концентрацию пережитого» [2, с. 264]. Говоря иначе, любой предмет в его философской интерпретации не исчерпывается одним значением и может располагать множеством смысловых центров. Нередко философы в процессе осмысления различных предметов или явлений сталкиваются с тем, что в однозначном, точном понятии невозможно уложить часть реальности, являющуюся внеязыковой. Понятие становится неполным и неточным, что побуждает к поиску иных средств для выражения представлений о действительности. Данный факт вполне объясняет то, 
что в процессе интерпретации предмета осмысления в философии нередко обращают внимание на особые языковые средства, в частности, метафоры. И здесь язык философии отражает уже не саму реальность, данную в опыте (эксперименте), а относится к некоей теоретической модели, включающей избранные абстрактные объекты. В этом случае перенос свойств предметов физического мира на образ философской идеи порождает глубинную способность невидимого влиять на видимое, невоспринимаемого - на воспринимаемое, мнимого - на явное. Другими словами, философ, чтобы донести свои мысли, идеи до читателя, использует уже привычное и понятное в его значении слово (близкое по смыслу к необходимому понятию) и наделяет его дополнительными (или даже новыми) смыслами. Стоит отметить, что прежние смыслы не отвергаются, но становятся своеобразной опорой новым смыслам. Данный процесс и есть формирование метафоры, которую Ортега-и-Гассет определял как «действие ума, с чьей помощью мы постигаем то, что не под силу понятиям» [4, с. 206]. Характеризуя возможности метафоры в мышлении о том, что «отдаленно» и «недосягаемо», он писал о ее возможности «удлинять радиус действия мысли», поскольку она способна обеспечить, по мнению философа, «практический доступ к тому, что брезжит на пределе допустимого» [4, с. 206]. Использование метафор не раз позволяло философам влиять на мышление людей, вызывать у них интерес, склонять их к принятию определенной (своей) точки зрения, а также находить приверженцев и последователей выдвигаемых концепций. Метафору как форму выражения философских идей использовали Зенон, Гераклит, Платон, Сократ, Августин, Анаксимен, Будда, Буридан, Ф. Бэкон, Р. Декарт, Евбулид, И. Кант, Конфуций, Ф. Ницше, О. Шпенглер, 3. Фрейд, Г. Сковорода, П. Юркевич, И. Ильин и др. Стоит отметить, что обращение к метафорам не только способствовало визуализации философских идей, добавляя им живых поэтических красок, но и давало возможность автору для более объемного выражения содержания значимого для него понятия. А неуловимые, в высшей степени абстрактные, мысли философа становились жизнеспособными ввиду того, что его неподвластные чувствам идеи конструировались на понятном обычному человеку языке.

Одними из наиболее ярких метафор, встречающихся в ряде философских концепций, являются метафоры, связанные с огнем. В истории культуры и философии огонь получил множество различных интерпретаций посредством разных «символических универсумов»: в обыденном языке, языке искусства, науки, мифологии. Феномен огня проблематизировался как в собственном своем бытии, так и использовался в различных вариантах его понимания для решения проблем бытия иных предметов (в том числе бытия культуры и различных ее феноменов). Оформление философских идей вокруг основных природных стихий (огонь, вода, земля и воздух), начиная с момента возникновенья философии, по мнению В. И. Плотникова, может объясняться тем, что «ближайшая природная стихия, в значительной мере уже покоренная культурой, неизмеримо проще поддавалась логике воображения, а потому и искусству догадки, умозрению или поэтическому творчеству» [2, с. 243]. Возможно, поэтому философская интерпретация феномена огня представлена широким спектром метафор: от тех, что связаны с окружающим миром - «мир есть вечный огонь» (в учении Гераклита); внутренними состояниями человека - «огненная страсть», «пепел любви», «огонь желаний» (в трудах 
авторов психоаналитических концепций 3. Фрейда, Г. Башляра и др.); как метафорой дара (огонь Прометея), до метафоры огня как процесса трансформации (в философии Ф. Ницше, О. Шпенглера и др.). Огонь в философских метафорах присутствует и как символ активности культуры, ее энергетический источник, творческое начало, импульс.

В течение многих лет ведутся бесконечные дискуссии ученых, философов о сущности и существовании культуры. Культура в своем многообразии, сложности, динамике остается неуловимой: ее содержание, особенности и тенденции развития не охватываются до конца не только одним, но и всем существующим набором дефиниций, предлагаемых в разных подходах к ее исследованию и осмыслению. Всякий раз она обнаруживает через свою недосягаемость для исследующего ее разума и его собственные границы. Все многообразие определений культуры, подходов и способов ее осмысления, изучения позволяет утверждать, что открытие культуры человечеству еще предстоит. И это открытие, как утверждал Л. Уайт, «встанет в один ряд с гелиоцентрической теорией Коперника или открытием клеточной основы всех форм жизни» [9, с. 147].

Осознание сущности культуры как особой сферы бытия - одна из актуальных философских проблем, которая не раз в истории человечества приобретала наравне с теоретическим практическое значение. Без определенного, осознанного ответа на проблемные вопросы бытия культуры, перспектив и приоритетов в ее развитии не удавалось, в конце концов, и решение более частных задач человеческого существования. Безусловно, наиболее пристальное внимание ученых и философов культура привлекает к себе в моменты крутых переломов (кризисов) в своем развитии.

Глубоко переживая кризисное состояние культуры, последнюю Фридрих Ницше представлял как результат борьбы двух равнодействующих и одновременно противоположных сил, как борьбу двух начал: аполонийского и дионисийского. Ницше, полагая, что метафоричность свойственна мышлению, нередко и сам обращается к метафорам, излагая свою концепцию культуры. Одной из таких метафор является метафора огня, которая несет важную смысловую нагрузку. С еe помощью возможна дистинкция между двумя началами культуры (аполонийским и дионисийским), одно из которых связано с представлением о культуре как существующей реальности, другое соответствует некой сверхреальности в культуре (как свобода творческого духа). Идеальное же состояние культуры Ницше видит в гармоничном взаимодействии этих начал, а огонь в его концепции формирует понятие некоего динамичного, ментального начала культуры. Но это начало выступает не в качестве исходной точки (из которой все выходит и куда возвращается), а как некий импульс, инициирующий энергетический толчок становления культуры (превалирования одного из начала). Под импульсом Ницше понимает волю, внутренний порыв, силу внутреннего огня, силу, которая может найти свое воплощение исключительно в искусстве, музыке в частности. Только она, по мнению философа, «есть тот очистительный дух», который способен вернуть утраченное «здоровье» культуре (кризис культуры Ницше нередко называет ее «болезнью») [12]. 
Исходя из того, что проблему упадка культуры Ницше рассматривает в качестве эстетического феномена, искусство здесь предстает как высшая форма проявления культуры. А причину декаданса культуры философ видит в утрате ее творческого начала - дионисийского. Именно оно в наибольшей степени соответствует характеристикам природной стихии огня. Для Ницше дионисийство «пламенное буйство», пляска Витта («Огни святого Антония»), выражающая «пламенную жизнь дионисийских безумцев» [12], тогда как господствующая на тот момент аполонийская культура - застывшая, тлеющая жизнь. Если принять взгляд философа на то, что дионисийское начало - непрекращающийся (вечный) процесс творческого становления (здесь философ обращается к Гераклиту, к его огню как потоку становления), то можно сказать, что в понятие воли Ф. Ницше включает активное взаимодействие творческих сил, «пламенное стремление» к идее «вечного возвращения», идее жизни. Эта воля выражается в способе затраты силы - превращения творческой энергии в жизнь через искусство, когда творческую личность охватывает «страстное вихреподобное горение» (определение художника В. Чекрыгина). «Воля» у Ницше также стала тем, из чего исходит всякое установление ценностей — «принципом установления ценностей» — волей волящей ценности, и началом (энергетическим началом), к которому вполне применимы качества огненной стихии. Это импульс, огненная вспышка, порыв, который приводит в действие все устремления человека. Этому соответствует понимание Ницше идеи формирования идеальной культуры как процесса «приручения огня», объединения двух противоборствующих начал, обретения целостности мира. В противном же случае культура вступает в период декаданса.

Вслед за Ницше тему декаданса культуры продолжает О. Шпенглер. В каждой культуре как живом организме, который рождается, живет и умирает, ее идея связана с уникальной душой - основой, полной живого (творческого) огня. А творческая деятельность человека - средство поддержания огненного начала души культуры в наивысшем состоянии. Состояние кризиса культуры философ описывает исходя из глубоких личных убеждений в приближающейся смерти европейской культуры, обращаясь при этом к метафоре огня. Так, бытие культуры О. Шпенглер видел в бесконечном «нарождении и умирании форм» (терминология Ф. А. Степуна) [7], тысячи огней, разгорающихся и потухающих. Каждый раз, рождаясь заново, душа дает культуре новую искру, но каким будет пламя новой культуры? Будет гореть живым огнем творчества или же ей предстоит угаснуть в «мертвой работе» цивилизации (что и происходило, по мнению философа, с западной культурой XIX в.) [11, с. 264]. Замена человеком культурных ценностей на утилитарные привело к умиранию созидательной энергии в душе культуры, «исчерпанию ее душевных сил» [10], что, в свою очередь, движет к смерти культуры, «угасанию ее души» [11, с. 329]. Призывая принять «смерть» культуры, Шпенглер, уверен, что культура вновь родится, но это будет другая культура, это будет иной огонь. Так как в океане человеческого бытия, которое О. Шпенглер именует как «Urseelentum», с некоей периодичностью вспыхивают огни «творящих духовных сил» (терминология С. Л. Франка). Эти самые огни и есть души будущих культур, которые, разгораясь огненными фонтанами новорожденной культуры, постепенно тускнеют и угасают [7]. Выражая душу культуры метафорой огня, философ представляет, что с ней связана конечная цель понимания существования культуры как 
процесса «вечно зарождающихся и умирающих форм» (по определению Ф. А. Степуна).

Осмысление бытия культуры, которое можно рассматривать в контексте интерпретации феномена огня, обнаруживается в концепции культуры П. А. Сорокина. В отличие от своих предшественников, П. Сорокин рассматривает вопросы не только обозначившегося кризиса культуры, но и размышляет над способом выхода последней из ситуации «большого пожара», бушующего в Западной Европе в начале двадцатого столетия. Указывая на внутреннюю динамичность культуры, ее развитие Сорокин видит в ряде сменяющих друг друга фаз, представленных им в качестве культурных суперсистем: идеациональной, чувственной и идеалистической. Смена фаз в его понимании есть смена мира смыслов, коренное изменение в мировоззрении и менталитете народов, их идейных и ценностных ориентаций. Видя в ценностях «фундамент каждой культуры» и определяя культуру в качестве ценностной системы (в первую очередь), философ считает, что именно культура задает точку отсчета развития социального организма (общества и человека) [11]. Так, идеациональная культура базируется на принципе сверхчувственности и сверхразумности Бога. Бог — высшая безусловная реальность, сверхчувственное и сверхразумное начало. Другими словами, вся культурная и социальная сфера преломляется через призму религиозного отношения к бытию. Земная жизнь лишь иллюзия жизни, временное пребывание человека в этом мире, тогда как подлинная реальность сверхчувственна, нематериальна. Созданный Богом человек наполнен «искрой божьей» («творческой искрой»), и единственная цель проявления его творческой энергии - это реализация божественных ценностей «во время краткого земного путешествия человека к вечности» [6, с. 20].

Смена эпох, связанная с развитием жизни и образа мышления, всегда несет и смену ценностных ориентиров. Несомненно, данный процесс не происходит «здесь и сейчас», и в определенный момент можно наблюдать формирование новых ценностных ориентиров, опирающихся на еще не отжившие старые, устоявшиеся ценности. Данный период в культуре определяется П. Сорокиным как развитие идеалистической культуры, признающей развитие двух типов ценностей, но при явном доминировании духа над материей, идеализма над материализмом. Это выражается в значительном перекосе в сторону идеализации мира. В качестве примера философ приводит культуру раннего Возрождения (Петрарка, Рафаэль и др.), время присутствия двух систем ценностей, которые не только взаимодополняют друг друга, но и взаимно ограничивают друг друга. Сорокин усматривает в этом ограничении симптомы «замирания» культуры, когда жизнь (как творческий огонь) не горит, а «только теплится». Перекос в сторону одной из систем ценностей (в данном случае отказ от духовных ценностей) способствует взрыву стихийных (природных) сил в человеке (его внутреннего огня), что подобно порыву ветра, раздувающего пламя тлеющего костра.

Это и происходит в момент смены идеалистической культуры чувственным типом культуры, которая характеризуется Сорокиным уже с использованием другой «огненной» метафоры - пожара, которая фиксирует уже процесс деструктивности в существовании культуры. Общество чувственной культуры начинает жить и мыслить в «котле мирового пожарища», в котором «до основания» сгорают ду- 
ховные (высшие) ценности. В уничтожении моральных, гражданских и религиозных ценностей П. Сорокин видит исчерпание созидательного творческого потенциала человека и его культуры, что и приводит последнюю в состояние тотального кризиса. Ярким примером здесь может служить чувственное искусство, отображающее лишь «поверхность окружающего мира» (часто довольно неприглядную), не проникая в глубину изображаемых вещей, предметов или явлений, тем самым оставляя недосягаемой их суть, превращая культуру в «эфемерный огонь жизни». $[14$, c. 434]. Как считал П. Сорокин, чувственной западноевропейской культуре грозит «закончить свое существование в смертельном пожарище». Но отличительной чертой концепции культуры П. Сорокина является отрицание тотальности и необратимости «смерти» культуры (предсказанной Шпенглером) и именно в этой «смертной агонии» западноевропейской культуры Сорокин видит рождение новой формы культуры и, как следствие, «высвобождение новых творческих сил», процесс, который возможен только через очищение «огнем пережитой катастрофы» [14, с. 269].

Подводя итог, можно сказать, что огонь в философской концепции культуры П. Сорокина символизирует некий энергетический источник (дух), благодаря которому все претерпевает изменение, духовное преображение и обретает новую форму. Огонь здесь - духовный свет, торжество жизни над смертью. Но при этом огонь - это стихия, которая без должного управления (наличия норм и ценностей) готова вырваться и уничтожить все вокруг — человека, культуру, мир.

Еще одной интерпретацией существа и генезиса культуры является психоаналитический взгляд на нее в учении 3. Фрейда. Учитывая факт, что сам он не ставил перед собой задачу формирования цельной концепции культуры, последняя в его концепции является продуктом сублимации первичной жизненной энергии - либидо, которое предстает в качестве движущей силы человеческой истории. Понятие «либидо» в творчестве Фрейда нередко соотносится с огнем, понимается как некий энергетический базис, источник движущей энергии (внутренней) человека, как источник его культурного творчества. Питание культуры через этот своеобразный источник приводит к его истощению, так как человек не располагает беспредельным запасом психической энергии. Достижение культурных целей, как отмечает Фрейд, отнимает энергию от собственной жизни человека. В связи с этим человеку необходимо научиться целесообразно распределять ее - контролировать степень горения своего огня (либидо). Исходя из того, что процесс развития культуры, как указывал в своей работе «Неудовлетворенность культурой» 3. Фрейд, требовал «отнять от сексуальности значительное количество сексуальной энергии», это приводило процесс развития общества к постоянному преодолению, внутренней борьбе [15]. Бушующее пламя человеческих страстей, являясь своеобразным энергетическим источником, постоянно требует выхода - разряжения в действии. Это вулканический огонь, вырывающийся из кратера эмоций в кризисные моменты жизни человека. Это демоническое пламя страсти в отношениях между людьми, которое символизирует накал эмоций. Погасить, приручить данное пламя возможно только сублимацией «огненной» энергии, направив ее на усиление человеческого сверх-я, которое может быть выражено в творчестве, гениальных открытиях и произведениях искусства [15]. 
Как показывают рассмотренные примеры концепций культуры, философы нередко обращались к различным «огненным метафорам», осмысливая важные философские проблемы бытия и актуального существования культуры. Огонь в этих метафорах помогал обозначить, выразить в языке ключевые идеи автора. Огонь в силу своей многозначности в культуре любого народа, сопряженности его собственных характеристик и свойств со всеми сторонами бытия человека и его мира (как материальными, так и духовными) всегда присутствует в культуре в качестве образного, символического средства для выражения ее значимых феноменов и действующих в ней сил. В языке философии и философском мышлении обращение к метафоре огня позволяет авторам философских концепций визуализировать свои идеи о содержании культуры, ее типах и тенденциях в ее развитии, дополняя возможности философских категорий и понятий или предваряя их появление.

Для философии культуры особое значение имеет интерпретация посредством огненных метафор начал, оснований культуры. Проблема начала является проблемой онтологии культуры. С. И. Ожегов и Н. Ю. Шведова, давая определение термину «начало» как первому моменту, понимают под «началом» исходный пункт или исходную точку, с которой начинает разворачиваться какое-либо действие, явление. Кроме того, начало - это также некая основа (первоисточник), причина, принцип [13]. Так, интерпретация «начала» в экзистенциональном ключе («начало мира») определяет его как импульс, посланный в «неродившееся пространство». Здесь «начало» есть момент зарождения мира [1].

Начало, понятое как исходная точка, дает возможность вести речь об этапах развития культуры; если начало - это первопричина, то в центре внимания оказывается конкретное содержание культуры, которое ею порождено как следствие действия этой причины. И огонь нередко интерпретировался в качестве такого начала, «огненного» энергетического основания культуры. Несмотря на различия в своем содержании, все культуры тождественны друг другу в этом своем основании, в своем огненном (духовном, ценностном) начале, которое является жизнеобеспечивающим, непосредственно связанным с жизнеспособностью культуры, а также противопоставляется тому, что снижает или даже подавляет жизненную энергию культуры (ее жизненную силу). При этом каждый раз суть этой жизненной энергии связывается с тем, что можно обозначить как энергетику культуры (ее дух, духовный центр, духовное единящее начало, ее идею). Это выражается в системе ценностей этой культуры, в их иерархии, в том, что стоит на верху этой иерархии, в своеобразной духовной парадигме конкретной культуры. На этом культура стоит и этим держится, выражая свой дух в языке, искусстве, философии. В этом энергетическом начале, в его содержательном своеобразии больше всего проявляется уникальность конкретной культуры. Каждая культура вырабатывает механизм удержания в себе этого живого начала, поддержания жизнеспособности. И здесь стоит вспомнить идею Гераклита об огне как огнелогосе. В ней огонь предстает как живая душа изменения, разумная субстанция, творящая мир в соответствии с законами и логикой. Огонь-Логос, выступающий как основание бытия культуры, это скрытый разум вещей, разумная связь мирового целого, его внутренняя мысль. Это сила, которая может все разрушить, если человек не научится ее упорядочивать, сдерживать и направлять. Поэтому в каждой культуре есть свои 
механизмы и культурные инструменты сдерживания этой силы - традиции, нормы, законы, правила, система ценностей и т. д. Положительной тенденцией является то, что в настоящее время при осмыслении культуры на эти механизмы начинают обращать активное внимание. Все эти сдерживающие инструменты основа содержательных различий, а то, что за ними стоит, по существу, одинаково. Это «энергия» культуры, «огонь», заложенный в ее основание. Насколько сильно человек позволит этому огню разгореться, будет ли его пламя ровным, дарящим свет и тепло, или же огню предстоит стать пожаром войны и очагом конфликтов, является сферой его (человека) ответственности. И избежать «апокалипсической катастрофы» возможно только через те творческие силы, которые способны привести человечество в «новую, величественную эру его истории», как и пророчествовал П. Сорокин [14], только через очищающий огонь.

Литература

1. Гумилев Н. С. Стихотворения и поэмы. (Библиотека поэта. Большая серия). 3-е изд. Л.: Сов. писатель, 1988. С. 466-472.

2. Многообразие жанров философского дискурса: учеб. пособие / под ред. В. И. Плотникова. Екатеринбург: Банк культурной информации, 2001. 276 с.

3. Ницше Ф. Шопенгауэр как воспитатель // Несвоевременные размышления. СПб.: Азбука, 1996. С. 183-272.

4. Ортега-и-Гассет Х. Эстетика. Философия культуры. М.: Искусство, 1991. С. 206.

5. Современная западная философия: словарь / сост. отв. ред. В. С. Малахов, В. П. Филатов. 2-е изд., перераб. и доп. М.: ТОН-Остожье, 1998. С. 292. C. 351.

6. Сорокин П. А. Главные тенденции нашего времени / пер. с англ. М.: Наука, 1997.

7. Освальд Шпенглер и закат Европы / Ф. А. Степун [и др.]. М., 1922. С. 48.

8. Тойнби А. Цивилизация перед судом истории: сб. / пер. с англ. Е. Д. Жаркова и др. М.: Айрис-пресс, 2006. 588 с.

9. Уайт Л. Энергия в эволюции культуры. Антология исследований культуры. СПб., 1997. C. 147.

10. Шпенглер О. Закат Европы: очерки морфологии мировой истории / пер. Н. Ф. Гарелина. Т. 1. Образ и действительность. Минск: Попурри, 1998. С. 688.

11. Sorokin P. A. Social and Cultural Dynamics. N.Y. 1937-1941. Vol. 1. P. 666 [Электронный ресурc]. URL: https://archive.org/details/in.ernet.dli.2015.84242 / (дата обращения: 07.06.2020).

12.Ницше Ф. Рождение трагедии из духа музыки [Электронный ресурс] / пер. Г. А. Рачинского. М.: Мысль, 1990. С. 26. URL: https://dom-knig.com/ (дата обращения: 23.05.2020).

13. Ожегов С. И., Шведова Н. Ю. Толковый словарь русского языка. М., 1993 [Электронный ресурc]. URL: http://lib.ru/ (дата обращения: 23.05.2020).

14. Сорокин П. А. Кризис... Катарсис... Харизма... Воскрешение... [Электронный pecypc] / пер. В. В. Сапова // Вестник Российской Академии наук. 1999. Т. 69, № 3. С. 269. URL: http://www.ras.ru/ (дата обращения: 23.05.2020).

15. Фрейд 3. Недовольство культурой [Электронный pecypc]. URL: https://librebook.me/ (дата обращения: 23.05.2020).

Статья поступила в редакцию 03.09.2020; одобрена после рецензирования 25.09.2020; принята к публикачии 28.09.2020. 


\section{COMPREHENSION OF THE FOUNDATIONS OF CULTURE BEING IN TERMS OF PHILOSOPHICAL METAPHORS OF FIRE}

\section{Tatyana N. Moiseenko}

Research Assistant of Philosophical Sciences Department, Chelyabinsk State Institute of Culture 36a/1Ordzhonikidze St., Chelyabinsk 454091, Russia tanechka_70@mail.ru

Abstract. The article substantiates the potential of metaphors associated with the phenomenon of fire for comprehension and interpreting culture in the philosophical concepts by F. Nietzsche, O. Spengler, Z. Freud and P. Sorokin. We have explained the heuristic meaning of fire metaphors in the philosophical and cultural discourse. The article presents the role of metaphors as independent means of philosophical thinking about the "unattainable", means of excogitating philosophical ideas; analyzes the meaning of fire metaphors in understanding the foundations (principles) of culture. Attention is focused on the problem of culture dynamics, and also on the possibilities of metaphors (as a substantiation of our thesis about the possibilities and meaning of the fire metaphor) in the analysis of the concepts of culture by the abovementioned authors. The problem of the beginning of culture is associated with the identification of the energetic (creative) principle of its existence.

Keywords: philosophy; culture; metaphor; fire; the beginning; energy; fire metaphor; culture being. 